\title{
Successful COVID-19 rescue therapy by extra-corporeal membrane oxygenation $(E C M O)$ for respiratory failure: a case report
}

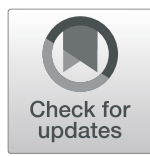

\author{
Michael S. Firstenberg ${ }^{1,2^{*}}$ (D), Philip F. Stahel ${ }^{1,3}$, Jennifer Hanna', Chakradhar Kotaru', Joseph Crossno Jr and \\ Joseph Forrester ${ }^{1}$
}

\begin{abstract}
Background: The value of extracorporeal membrane oxygenation (ECMO) for patients suffering from novel coronavirus disease 2019 (COVID-19) as a rescue therapy for respiratory failure remains controversial and associated with high mortality rates of 50 to $82 \%$ in early reports from Wuhan, China. We hypothesized that patient outcomes would be improved at our tertiary cardiothoracic surgery referral center with a protocolized team-approach for ECMO treatment of patients with severe COVID-19 disease.

Case presentation: A 51-year-old healthy female developed severe acute respiratory syndrome coronavirus 2 (SARS-CoV-2) bilateral pneumonia while vacationing in Colorado with her family. She was transferred to our facility for a higher level of care. Her respiratory status continued to deteriorate despite maximized critical care, including prone positioning ventilation and nitric oxide inhalation therapy. Veno-venous ECMO was initiated on hospital day 7 in conjunction with a 10-day course of compassionate use antiviral treatment with remdesivir. The patient's condition improved significantly and she was decannulated from ECMO on hospital day 17 (ECMO day 11). She was successfully extubated and eventually discharged to rehabilitation on hospital day 28.

Conclusion: This case report demonstrates a positive outcome in a young patient with COVID-19 treated by the judicious application of ECMO in conjunction with compassionate use antiviral treatment (remdesivir). Future prospective multi-center studies are needed to validate these findings in a larger cohort of patients.
\end{abstract}

Keywords: Coronavirus, COVID-19, SARS-CoV-2, Extra-corporeal membrane oxygenation, Lung injury, Remdesivir treatment

\section{Background}

The novel coronavirus disease 2019 (COVID-19) global pandemic is associated with a high estimated case-fatality rate of around 3.5\% [1-5]. The main clinical feature of severe acute respiratory syndrome coronavirus 2 (SARS$\mathrm{CoV}-2$ ) infection is represented by bilateral pneumonia with radiological signs of ground glass opacification [6].

\footnotetext{
* Correspondence: msfirst@gmail.com

${ }^{1}$ The Medical Center of Aurora, 1501 South Potomac St, Aurora, CO 80012, USA

${ }^{2}$ Cardiothoracic and Vascular Surgery, The Medical Center of Aurora, $1444 \mathrm{~S}$. Potomac Street, Suite 200, Aurora, CO 80012, USA

Full list of author information is available at the end of the article
}

One third of symptomatic COVID-19 patients require intensive care unit (ICU) admission and around 30\% of these patients show signs of acute respiratory distress syndrome (ARDS) [6]. The high mortality of SARS-CoV-2 pneumonia is associated with intractable respiratory failure in up to $98 \%$ of all non-survivors, based on retrospective observational cohort studies from Wuhan, China [7, 8]. Extra-corporeal membrane oxygenation (ECMO) represents a potentially life-saving modality for patients with terminal respiratory failure [9]. However, early experiences from COVID-19 "hot zones" in China reported a high mortality rate of $50-82 \%$ in adult patients with ARDS

(C) The Author(s). 2020 Open Access This article is licensed under a Creative Commons Attribution 4.0 International License, which permits use, sharing, adaptation, distribution and reproduction in any medium or format, as long as you give appropriate credit to the original author(s) and the source, provide a link to the Creative Commons licence, and indicate if changes were made. The images or other third party material in this article are included in the article's Creative Commons licence, unless indicated otherwise in a credit line to the material. If material is not included in the article's Creative Commons licence and your intended use is not permitted by statutory regulation or exceeds the permitted use, you will need to obtain permission directly from the copyright holder. To view a copy of this licence, visit http://creativecommons.org/licenses/by/4.0/ The Creative Commons Public Domain Dedication waiver (http://creativecommons.org/publicdomain/zero/1.0/) applies to the data made available in this article, unless otherwise stated in a credit line to the data. 
from SARS-CoV-2 pneumonia $[10,11]$. In the present case report, we describe the successful rescue treatment of a critically ill patient with respiratory failure due to COVID-19 and discuss the critical variables for effective ECMO therapy in this highly vulnerable patient cohort.

\section{Case presentation}

A 51-year-old female travelled from Illinois to Colorado for a winter vacation with her family. She was a previous smoker ( $<1$ pack/day) and had been abstinent for more than 10 years. Past medical history consisted of a remote Caesarean section, medically controlled hypertension, no know allergies, and minimal social alcohol consumption. On March 6, 2020, she presented with an unstable ankle fracture to a local hospital and underwent surgery by open reduction with internal fixation the following day. Prior to her surgery, she had reported "mild cold symptoms". Upon awakening from general anesthesia, during extubation she was noted to have an unusual consistency of her respiratory secretions described as "pink and frothy". Empirical broad-spectrum antibiotics were initiated for the treatment of a presumed aspiration pneumonitis. The patient deteriorated over the subsequent days with fever, hypoxemia, and bilateral pulmonary infiltrates. She required intubation and mechanical ventilation. COVID-19 testing was performed by nasopharyngeal swab and was positive for SARS-CoV-2 by polymerase chain reaction (PCR). The patient was transferred to our center, an established ECMO program, for higher level of care 1 week after her initial admission.

The timeline of the patient's course of events is summarized in Table 1.

Upon arrival to our facility, she was hemodynamically stable, sedated, intubated and mechanically ventilated on $60 \% \mathrm{FiO}_{2}$ and $10 \mathrm{~cm} \mathrm{H}_{2} \mathrm{O}$ positive end-expiratory pressure (PEEP). Figure 1 demonstrates the patient's chest $\mathrm{X}$-ray on admission. She was admitted to our designated COVID-cohorting unit in the ICU and placed with strict respiratory droplet isolation precautions in a negative airflow room. Her admission laboratory studies demonstrated a low white blood cell count of $3110 / \mu \mathrm{L}$ with lymphocytopenia $(22.5 \%$ or $700 / \mu \mathrm{L})$. A bedside transthoracic echocardiogram showed normal left and right ventricular function, no valvular abnormalities, and normal estimated pulmonary artery pressures. By hospital day 2, her oxygen requirements increased and intermittent prone positioning was initiated in conjunction with pharmacologic paralysis and inhaled nitric oxide treatment.

Within the next few days, the patient's pulmonary compliance and hypoxemia worsened. Isolated endorgan pulmonary dysfunction persisted despite maximal ventilator support resulting in a $\mathrm{PaO}_{2} / \mathrm{FiO}_{2}$ ratio of 66 while still receiving inhaled nitric oxide iNO at $40 \mathrm{ppm}$. The arterial blood gas analysis (ABGA) showed a $\mathrm{pH}$ 7.36, $\mathrm{pCO}_{2} 45 \mathrm{mmHg}$, and $\mathrm{pO}_{2} 66 \mathrm{mmHg}$. The patient had a calculated "Respiratory ECMO Survival Prediction" (RESP) score of 1 with a risk class III and an estimated ECMO survival probability of 57\% [12].

Percutaneous femoral-femoral veno-venous ECMO support was initiated on day 7 of hospitalization. In brief, following systemic heparinization (10,000 units; maintenance target PTT 40-60 s), cannulation was accomplished with a 21-French venous multi-stage drain and a 21-French single-stage inflow cannula connected to a CardioHelp ${ }^{\text {Ta }}$ extra-corporeal support system (Maquet Cardiovascular, Wayne, NJ). Initial ECMO settings were $3.81 / \mathrm{min}$ flow, 3.21 of gas sweep, and ECMO $\mathrm{FiO}_{2}$ of 1.0. A lung protective ventilator strategy was initiated with an airway pressure release ventilation (APRV) mode (rate: 16 , pressures: $28 / 10, \mathrm{FiO}_{2}$ : 0.8 , inhaled nitric: $20 \mathrm{ppm}$, and plateau pressures were limited to 30 $\mathrm{mmHg}$ ). Antiviral therapy with remdesivir (RDV / GS5734; Gilead Sciences Inc., Foster City, CA) was initiated on hospital day 9 under a humanitarian use protocol for "compassionate use" indication [13], with a loading dose

Table 1 Summary of the timeline of events

\begin{tabular}{|c|c|c|c|}
\hline$\overline{\text { Date }}$ & Event & Hospital day \# & ECMO day \# \\
\hline March 6, 2020 & Ankle fracture & & \\
\hline March 7, 2020 & ORIF ankle fracture & & \\
\hline March 13, 2020 & Transfer to our facility & 1 & \\
\hline March 15, 2020 & Nitric oxide and prone therapy initiated & 3 & \\
\hline March 19, 2020 & ECMO initiated & 7 & 1 \\
\hline March 21, 2020 & Remdesivir initiated & 9 & 3 \\
\hline March 29, 2020 & ECMO decannulation & 17 & 11 \\
\hline March 31, 2020 & Liberated from invasive mechanical ventilation & 19 & 13 \\
\hline April 2, 2020 & Transfer to floor, transition to 2 I nasal cannula & 21 & 15 \\
\hline April 9, 2020 & Discharge to rehabilitation & 28 & 22 \\
\hline
\end{tabular}

Abbreviations: ECMO Veno-venous extracorporeal membrane oxygenation, ORIF Open reduction with internal fixation 


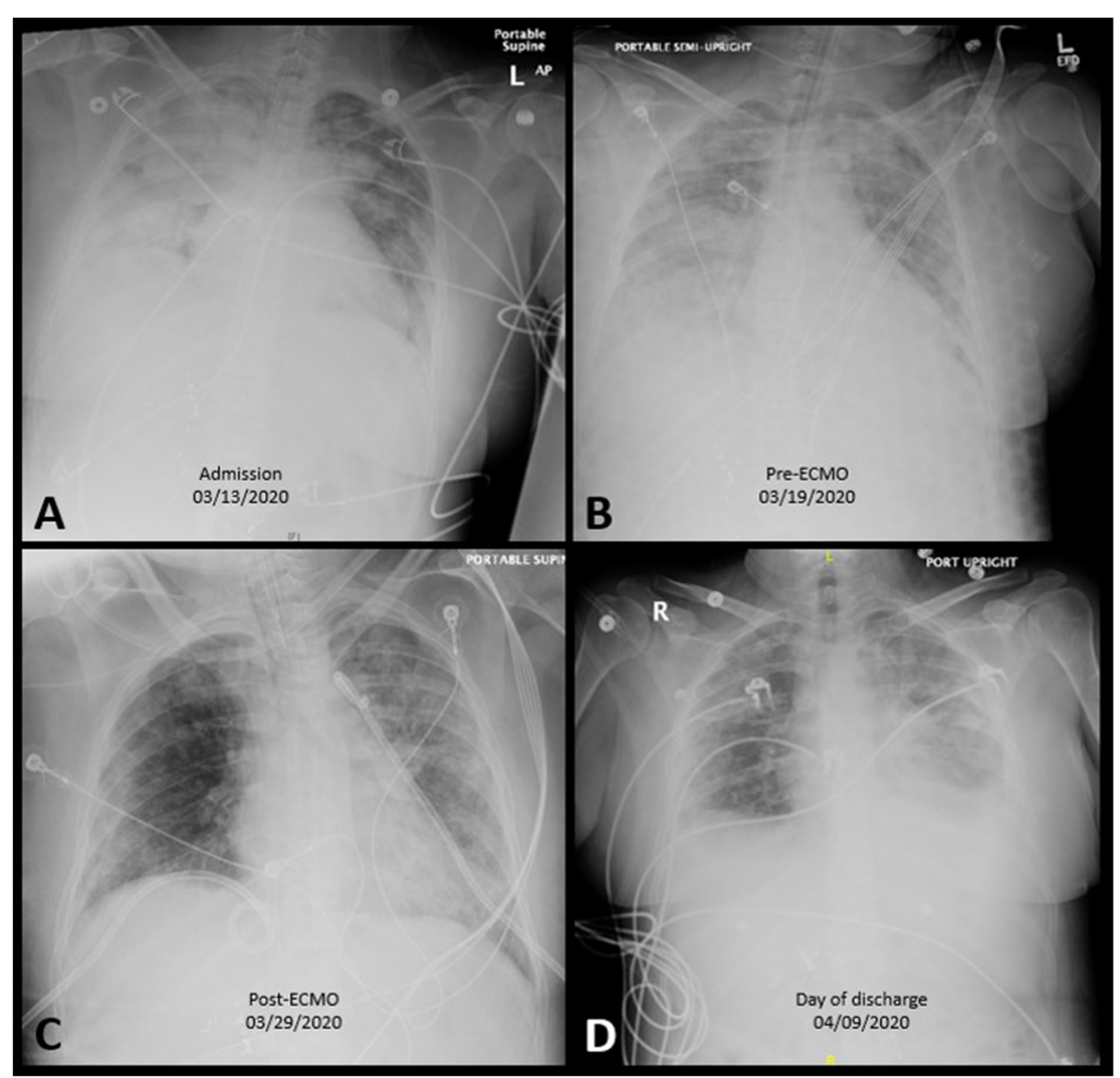

Fig. 1 The patient's chest X-rays on the day of admission (a); day of ECMO cannulation (b); day of ECMO decannulation (c); and day of discharge to rehabilitation $(\mathbf{d})$

of $200 \mathrm{mg}$ RDV intravenous on the first day, and oncedaily maintenance doses of $100 \mathrm{mg}$ RDV intravenous for a total treatment duration of 10 days.

A repeat echocardiogram showed no change in her left or right ventricular size or function. A bedside ultrasound demonstrated increasing bilateral pleural effusions which were managed by percutaneous drainage with bilateral 14-French chest tubes. The patient's pulmonary compliance, oxygenation, and ventilation, gradually improved over the subsequent days, and the ECMO sweep was slowly weaned (ventilator settings at pressure control; mean airway: $25 \mathrm{mmHg}$; rate 25; $\mathrm{FiO}_{2}$ 0.50; inhaled nitric oxide $20 \mathrm{ppm}$ ). Subsequently, the ECMO gas sweep was weaned off and the patient was successfully decannulated at the bedside on ECMO day 11 (hospital day 17). Her overall pulmonary function improved to the point in which she was extubated to heated high-flow oxygen. The patient's oxygen requirements were weaned to 21 nasal cannula on post-ECMO day 4 (hospital day 21). Room air blood gas analysis revealed $\mathrm{pH} 7.46 ; \mathrm{pCO}_{2} 33.6$ $\mathrm{mmHg} ; \mathrm{pO}_{2} 74.4 \mathrm{mmHg} ; \mathrm{HCO}_{3}-23 \mathrm{mEq} / \mathrm{L}, \mathrm{SO}_{2} 94 \%$.
A limited bedside spirometry yielded a negative inspiratory force (NIF) of $-50 \mathrm{mmHg}$.

Two repeat COVID-19 tests were negative for SARSCoV-2 prior to discharge form the hospital. The patient was discharged to a rehabilitation facility on hospital day 28 requiring $2-31 /$ minute of supplement oxygen which was weaned to room air within the week. At discharge, she was weak but able to stand and walk short distances and had an otherwise normal neurologic examination. Upon discharge she was greeted by a large group of health care providers as part of a farewell ceremony for our COVID-19 survivor (Fig. 2).

\section{Discussion}

The role of ECMO for rescue therapy of respiratory failure in critically ill COVID-19 patients remains controversial $[10,11,14,15]$. In this case report, we present a successful ECMO salvage case in a 51-year-old patient with bilateral SARS-CoV-2 pneumonia and refractory respiratory failure. We illustrate the technical aspects and crucial variables related to the indication and the ultimate positive outcome of this patient. Of note, our ECMO 


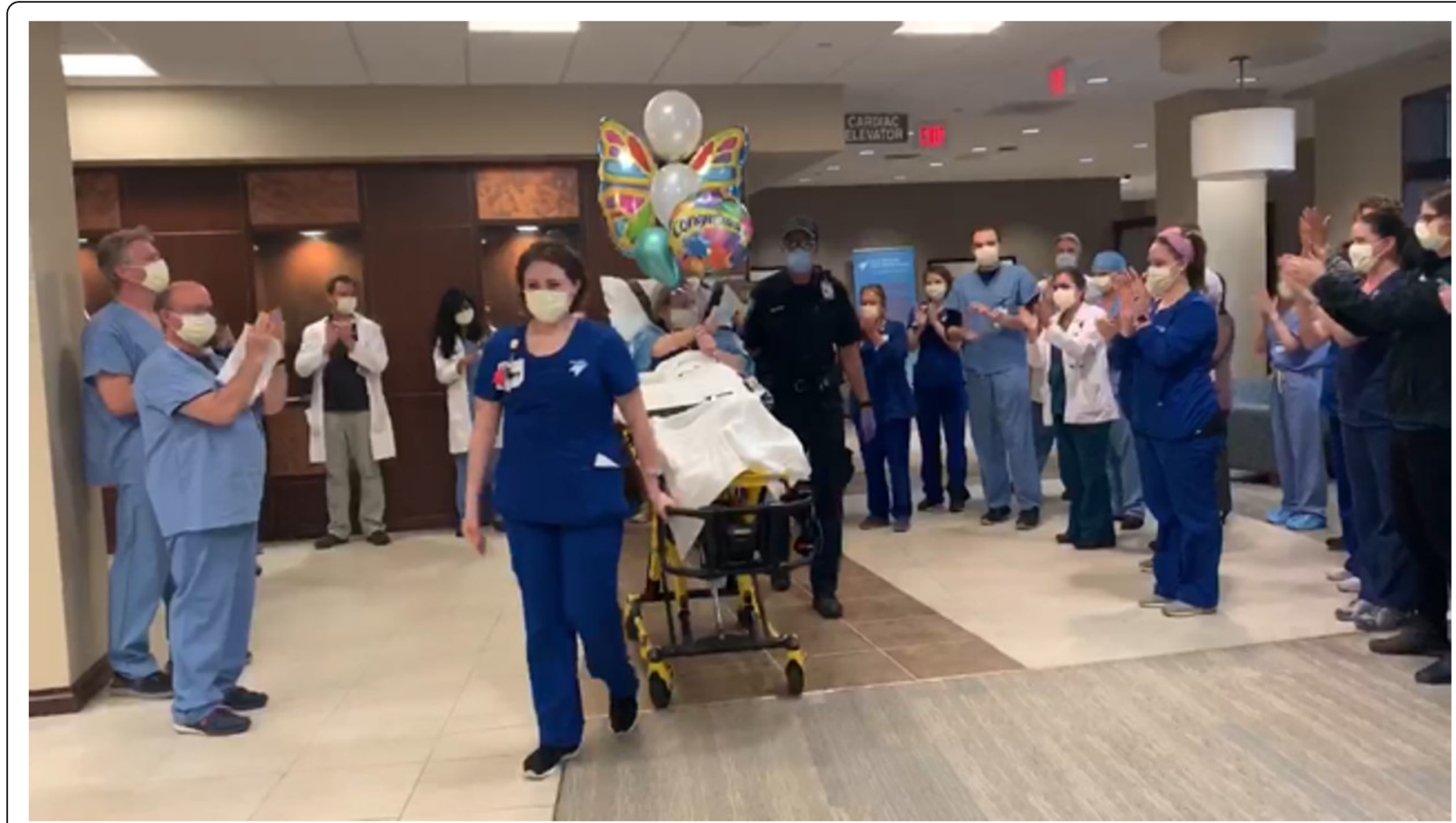

Fig. 2 Farewell reception by hospital staff at the Medical Center of Aurora to the COVID-19 survivor discharging to rehabilitation on hospital day 28

program consists of a multi-disciplinary team of specialists in which all major clinical decisions on ECMO patients are discussed during comprehensive twice daily team rounds attended by intensivists, cardiac surgeons, perfusionists, critical care nurses, pharmacy, and respiratory therapy, as previously described [16]. Monitoring of the ECMO circuit is performed by the perfusion team with 24/7 in-house coverage [16]. The current literature established a consensus that optimal outcomes in patients with profound respiratory failure and ARDS are achieved at specialized centers with full institutional commitment to advanced respiratory therapies [17].

Consistent with current guidelines by the Extracorporeal Life Support Organization (ELSO), our institution has embraced the concept that ECMO should only be considered at programs that have established and dedicated programs [18]. Figure 3 demonstrates the decision-making algorithm for ECMO consideration, endorsed by the ELSO guidelines [17, 18]. In addition to the ELSO guidelines we utilize the RESP score developed by ELSO to determine optimal candidates for ECMO intervention. Conversely, while salvage therapies might be considered outside of an existing program, in part due to the poor outcomes associated with this approach, centers are discouraged from embarking on ECMO program development at this time for the singular purpose of providing support for COVID-19 patients [18, 19]. Another key component of the successful outcome in the patient presented in this report is the timing of the initiation of therapy. While the literature reports varying thresholds in which veno-venous ECMO should be considered for acute respiratory failure, the general indications are profound respiratory failure refractory to conventional medical and ventilator management $[9,20$, 21]. This includes preceding attempts for "salvage" therapies with inhaled nitric oxide, prone positioning ventilation, and judicious use of paralytic agents $[9,20,21]$. Patients with profound hypoxemia, hypercapnia, respiratory acidosis, and worsening pulmonary compliance in the absence of mechanical causes are typically considered ECMO candidates [9, 20,21]. Contraindications to ECMO include concerns for acute neurologic insults, such as anoxic brain injury, contraindications to anticoagulation, and baseline comorbidities that predict either futility of ECMO or limited 2-year survival [9, 20, 21]. Current indications for ECMO in COVID-19 patients were recently proposed based on the early experience with the pandemic in China [22, 23]. As the pandemic spreads and resources (such as ECMO circuits) become limited, we advocate potentially limiting ECMO to those patients who have the best predicted outcomes. While the Survival After Veno-arterial (SAVE) and RESP scores [12] are helpful in selecting patients, they do not inherently account for poor ECMO outcomes such as acute or worsening end-organ damage and advanced age. We advocate ECMO for those patients with isolated single 


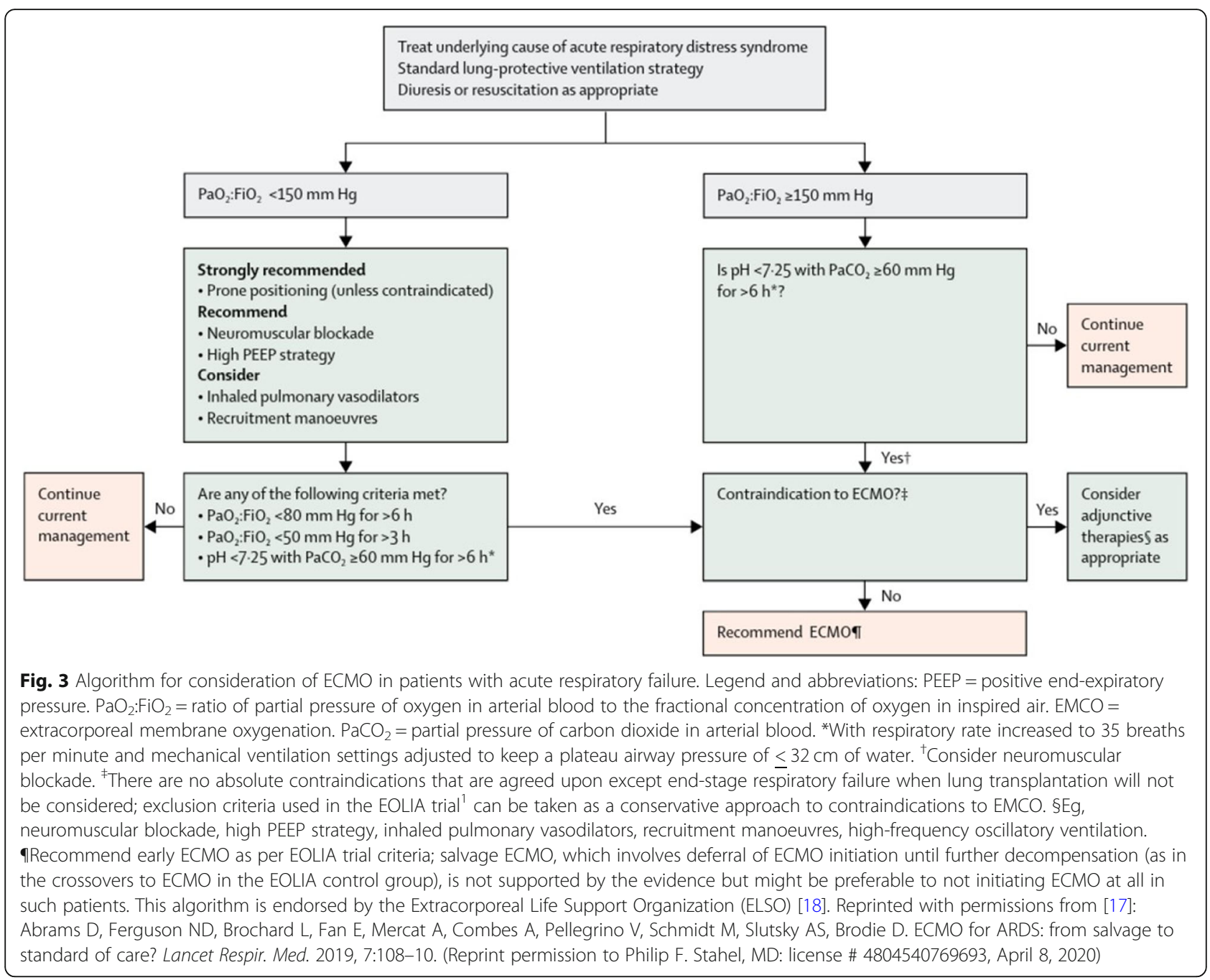

organ (pulmonary) dysfunction, few co-morbidities, and limited acute - and potentially reversible - end-organ dysfunction. Appropriate candidates should also probably be relatively young and otherwise hemodynamically stable.

As shown in this case report, the most crucial aspect to initiating therapy is the timing between reaching the threshold for indications and the decision to start therapy. While it is reasonable to consider adjuvant therapies - like inhaled nitric oxide and prone positioning ventilation, the care team must define clear thresholds for when the potential success of these adjunctive therapies may be considered exhausted and ECMO therapy should be considered. In the context of COVID-19 patients whose respiratory capacity can deteriorate very quickly, the decision to initiate therapy must be anticipated in advance and before the onset of potentially irreversible end-organ dysfunction. Unequivocal thresholds for considering ECMO are particularly important in this current COVID-19 pandemic as concerns of limited resources are prompting discussions of rationing therapies to those who might benefit the most from their use [24]. It is also important to realize that ECMO might have other potential benefits beyond supporting oxygenation and ventilation needs. When configured in a veno-arterial mode, cardiac output for patients in acute systolic heart failure can be supported [20,21]. Since COVID-19 is also associated with hyperpyrexia and cytokine storm, all of which can increased metabolic and oxygenation requirements, ECMO may also play a role in active quiescence of COVID-19 patients [18]. Preliminary United States Food and Drug Administration (FDA) authorization has been given to special "ECMO filters" that might assist in viral clearance (www.fda.gov/media/136867/download).

Various other root causes can potentially contribute to the poor outcomes associated with ECMO use in SARSCoV-2 infected patients [23]. Health care facilities that are not experienced in the management of these extremely ill and complex patients, especially if their respective experience is restricted to a few select patients, may have worse outcomes than established tertiary- 
referral ECMO centers [16]. This idea of referral to specialized ECMO centers also feeds into the concerns of patient selection and the timing of initiation of therapy delay in initiation of ECMO might predispose to a potentially worse outcome as the patient might have already reached a "point of no return" with regard to irreversible pathophysiology and evolving multi-organ dysfunction.

Concerns were recently raised that ECMO may contribute to the lymphopenia observed in COVID-19 patients thereby deteriorating the patient's cellular immune response and ability to clear the SRAS-CoV-2 pathogen effectively [14]. The extra-corporeal circuit has been shown to exaggerate an already dysfunctional immune system [25] and this adverse effect may negatively impact the outcomes of COVID-19 patients [14]. The role of immunemodulating therapies in the setting of advanced COVID19 infections in mitigating the "cytokine storm" leading to hyperinflammation and adverse outcomes is a topic of intense ongoing investigation [25-28].

It is imperative to understand that ECMO neither treats nor cures a disease, as the fundamental principle of ECMO consists of allowing the lungs to "rest" while the primary therapy, such as antiviral treatment, can take effect with less concern for ventilator-induced lung injury $[29,30]$. This notion is confirmed in the current case report, where the beneficial adjunctive effects of ECMO likely supported the patient's viral clearance by the antiviral therapy through the compassionate use indication for remdesivir [13]. An additional benefit of ECMO is to provide improved tissue oxygenation, carbon dioxide clearance, and systemic acid-base balance resolution to avoid end-organ physiologic shock, all of which are significant causes of mortality in the COVID-19 patient [31].

Fundamentally, ECMO should never be considered a primary therapy for any form of acute lung injury, but rather utilized as a lung-protective adjuvant modality that promotes a physiological respite and a "biological milieu" for lung healing and recovery. While the scientific evidence for the benefit of ECMO therapy in patients with severe COVID-19 still awaits further validation [32], the consideration of early referral of patients with respiratory failure from SARS-CoV-2 pneumonia to designated centers of excellence appears justified from a patient safety perspective.

\section{Conclusion}

This case report demonstrates a positive outcome in a young, critically ill patient after judicious application of ECMO for respiratory failure due to SARS-CoV-2 pneumonia. If ECMO is considered as a treatment for COVID19 , we suggest timely referral to a tertiary center with established expertise and standardized ECMO protocols. Future prospective multi-center studies are needed to validate these findings in a larger cohort of patients.

\section{FDA clearance}

The ECMO treatment described in this case report represents an FDAapproved indication. The antiviral therapy with remdesivir was approved by the FDA under the compassionate use protocol.

\section{Authors' contributions}

MSF provided the ECMO therapy and cardiothoracic consultation expertise for the multidisciplinary care of the patient described in this case report. PFS and MSF designed the case report and provided the first draft of the manuscript. JC, $\mathrm{CK}$, and JF provided the critical care to the patient described in this case report. All authors provided critical feedback and input to the manuscript revisions and read and approved the final version of this case report.

\section{Funding}

There were no external funding sources for this case report.

\section{Availability of data and materials}

Please contact the author for data requests.

\section{Ethics approval and consent to participate}

Ethics board approval is not applicable for a case report.

\section{Consent for publication}

Written informed consent was obtained by the patient described in this case report for publication of the manuscript including all pertinent data, protected health information, and according images, radiographs, and photographs. A copy of the written consent is available to the editorial board upon request.

\section{Competing interests}

MSF has served as scientific and educational consultant to Maquet Cardiovascular LLC, and as such has received funding for travel and financial support for educational activities related to ECMO technology. PFS is employed by HCA Healthcare in his role as the Chief Medical Officer at the Medical Center of Aurora. None of the other authors have relevant disclosures or conflicts of interest related to this manuscript. The CardioHelp ${ }^{\mathrm{TM}}$ extra-corporeal support system (Maquet Cardiovascular, Wayne, NJ) is not approved by the United States Food and Drug Administration for long-term use as described in this report.

\section{Author details}

${ }^{1}$ The Medical Center of Aurora, 1501 South Potomac St, Aurora, CO 80012, USA. ${ }^{2}$ Cardiothoracic and Vascular Surgery, The Medical Center of Aurora, 1444 S. Potomac Street, Suite 200, Aurora, CO 80012, USA. ${ }^{3}$ Department of Specialty Medicine, College of Osteopathic Medicine, Rocky Vista University, Parker, CO 80134, USA.

Received: 21 April 2020 Accepted: 28 April 2020

Published online: 08 May 2020

\section{References}

1. Zhou $P$, Yang $X L$, Wang $X G$, et al. A pneumonia outbreak associated with a new coronavirus of probable bat origin. Nature. 2020;579:270-3.

2. Velavan TP, Meyer CG. The COVID-19 epidemic. Tropical Med Int Health. 2020;25:278-80.

3. Cheng ZJ, Shan J. 2019 novel coronavirus: where we are and what we know. Infection. 2020;48(2):155 Feb 18, Epub ahead of print.

4. Stahel PF. How to risk-stratify elective surgery during the COVID-19 pandemic? Patient Saf Surg. 2020;14:8.

5. Bhatraju PK, Ghassemieh BJ, Nichols M, et al. Covid-19 in critically ill patients in the Seattle region - case series. N Engl J Med. 2020; March 30, Epub ahead of print..

6. Cao Y, Liu X, Xiong L, Cai K. Imaging and clinical features of patients with 2019 novel coronavirus SARS-CoV-2: a systematic review and meta-analysis. Jed Virol. 2020; April 3, Epub ahead of print

7. Zhou F, Yu T, Du R, et al. Clinical course and risk factors for mortality of adult inpatients with COVID-19 in Wuhan, China: a retrospective cohort study. Lancet. 2020;395(10229):1054-62.

8. Yang $X, Y u Y, X u$ J, et al. Clinical course and outcomes of critically ill patients with SRAS-CoV-2 pneumonia in Wuhan, China: a single-centered, retrospective, observational study. Lancet Respir Med. 2020; Feb 24, Epub ahead of print. 
9. Firstenberg MS. Evolution of ECMO from salvage to mainstream supportive and resuscitative therapy. In: Firstenberg MS, editor. Extracorporeal membrane oxygenation: advances in therapy. Rijeka: InTech Open; 2016. p. 2-8.

10. Li X, Guo Z, Li B, Zhang X, Tian R, Wu W, Zhang Z, Lu Y, Chen N, Clifford SP, Huang J. Extracorporeal membrane oxygenation for coronavirus disease 2019 in Shanghai, China. ASAIO J. 2020; March 30, Epub ahead of print.

11. Namendys-Silva SA. ECMO for ARDS due to COVID-19. Heart Lung. 2020; March 26, Epub ahead of print.

12. Klinzing $S$, Wenger $U$, Steiger $P$, Starck CT, Wilhelm M, Schuepbach RA, Maggiorini M. External validation of scores proposed for estimation of survival probability of patients with severe adult respiratory distress syndrome undergoing extracorporeal membrane oxygenation therapy: a retrospective study. Crit Care. 2015;19:142.

13. Grein J, Ohmagari N, Shin D, et al. Compassionate use of remdesivir for patients with severe Covid-19. N Engl J Med. 2020; April 10, Epub ahead of print

14. Henry BM. COVID-19, ECMO, and lymphopenia: a word of caution. Lancet Respir Med. 2020;8(4):e24.

15. Zhang C, Huang S, Zheng F, Dai Y. Controversial treatments: an updated understanding of the coronavirus disease 2019. J Med Virol. 2020; March 26, Epub ahead of print.

16. McCallister D, Pilon L, Forrester J, Alsaleem S, Kotaru C, Hanna J, Hickey G, Roberts R, Douglass E, Libby M, Firstenberg MS. Clinical and administrative steps to the ECMO program development; 2019. https://doi.org/10.5772/ intechopen.84838. www.intechopen.com/books/advances-in-extracorporealmembrane-oxygenation-volume-3/clinical-and-administrative-steps-to-theecmo-program-development.

17. Abrams D, Ferguson ND, Brochard L, Fan E, Mercat A, Combes A, Pellegrino $V$, Schmidt M, Slutsky AS, Brodie D. ECMO for ARDS: from salvage to standard of care? Lancet Respir Med. 2019;7:108-10.

18. ELSO guidance document: ECMO for COVID-19 patients with severe cardiopulmonary failure (March 24, 2020). www.elso.org.

19. Henry BM, Lippi G. Poor survival with extracorporeal membrane oxygenation in acute respiratory distress syndrome (ARDS) due to coronavirus disease 2019 (COVID-19): pooled analysis of early reports. J Crit Care. 2020; April 1, Epub ahead of print.

20. Anand S, Jayakumar D, Aronow WS, Chandy D. Role of extracorporeal membrane oxygenation in adult respiratory failure: an overview. Hosp Pract. 2016:44:76-85

21. Del Sorbo L, Cypel M, Fan E. Extracorporeal life support for adults with severe acute respiratory failure. Lancet Respir Med. 2014:2:154-64.

22. Li M, Gu SC, Wu XJ, Xia JG, Zhang Y, Zhan QY. Extracorporeal membrane oxygenation support in 2019 novel coronavirus disease: indications, timing, and implementation. Chin Med J. 2020; Feb 28, Epub ahead of print.

23. Hong $X$, Xiong J, Feng Z, Shi Y. Extracorporeal membrane oxygenation (ECMO): does it have a role in the treatment of severe COVID-19? Int Infect Dis. 2020; April 3, Epub ahead of print.

24. Steinberg E, Balakrishna A, Habboushe J, Shawl A, Lee J. Calculated decisions: COVID-19 calculators during extreme resource-limited situations. Emerg Med Pract. 2020;22(4 Suppl):CD1-5.

25. Millar JE, Fanning JP, McDonald Cl, McAuley DF, Fraser JF. The inflammatory response to extracorporeal membrane oxygenation (ECMO): a review of the pathophysiology. Crit Care. 2016;20:387.

26. Qin C, Zhou L, Hu Z, Zhang S, Yang S, Tao Y, Xie C, Ma K, Shang K, Wang W, Tian DS. Dysregulation of immune response in patients with COVID-19 in Wuhan, China. Clin Infect Dis. 2020; March 12, Epub ahead of print.

27. McGonagle D, Sharif K, O'Regan A, Bridgewood C. The role of cytokines including interleukin-6 in COVID-19 indeuced pneumonia and macrophage activation syndrome-like disease. Autoimmun Rev. 2020; April 3, Epub ahead of print.

28. Zhang C, Wu Z, Li JW, Zhao H, Wang GQ. The cytokine release syndrome (CRS) of severe COVID-19 and interleukin-6 receptor (IL-6R) antagonist tocilizumab may be the key to reduce the mortality. Int J Antimicrob Agents. 2020; March 29, Epub ahead of print.

29. Araos J, Alegria L, Garcia P, Cruces P, Soto D, Erranz B, Amthauer M, Salomon T, Medina T, Rodriguez F, Ayala P. Near-apneic ventilation decreases lung injury and fibroproliferation in an acute respiratory distress syndrome model with extracorporeal membrane oxygenation. Am J Respir Crit Care Med. 2019;199:603-12

30. Sen A, Callisen HE, Alwardt CM, Larson JS, Lowell AA, Libricz SL, Tarwade P, Patel BM, Ramakrishna H. Adult venovenous extracorporeal membrane oxygenation for severe respiratory failure: current status and future perspectives. Ann Card Anaesth. 2016;19:97-111.

31. Fan E, Gattinoni L, Combes A, Schmidt M, Peek G, Brodie D, Muller T, Morell A, Ranieri VM, Pesenti A, Brochard L. Venovenous extracorporeal membrane oxygenation for acute respiratory failure: a clinical review from an international group of experts. Intensive Care Med. 2016:42:712-24.

32. Alhazzani W, Møller MH, Arabi YM, et al. Surviving sepsis campaign: guidelines on the management of critically ill adults with coronavirus disease 2019 (COVID-19). Crit Care Med. 2020; March 27, Epub ahead of print.

\section{Publisher's Note}

Springer Nature remains neutral with regard to jurisdictional claims in published maps and institutional affiliations.
Ready to submit your research? Choose BMC and benefit from:

- fast, convenient online submission

- thorough peer review by experienced researchers in your field

- rapid publication on acceptance

- support for research data, including large and complex data types

- gold Open Access which fosters wider collaboration and increased citations

- maximum visibility for your research: over $100 \mathrm{M}$ website views per year

At BMC, research is always in progress.

Learn more biomedcentral.com/submissions 